\section{A Simple Model of Limited Stock Market Participation}

\author{
Hui Guo
}

T he 1998 Survey of Consumer Finance data shows that only 48.8 percent of U.S. households owned stocks, either (i) directly or (ii) indirectly through mutual funds. In addition, there is a close relationship between shareholding and wealth. In 1998, 93 percent of the richest 1 percent of the population owned stocks; the richest 10 percent owned 85 percent of total stocks and mutual funds, compared with 51 percent of total savings deposits. Meanwhile, the average stock return is "abnormally" higher than the average government bond return. ${ }^{1}$ In this paper, I try to explain this shareholding puzzle-why many people do not hold stocks given that stocks outperform government bonds by a large margin.

It is costly to collect and process information about stock markets. Bertaut (1997) finds that better-educated people are more likely to hold stocks, even after controlling for variables such as wealth, current income, and unemployment risk. He interprets education as a measure of the ability to process information about the market and investment opportunities. However, information costs are not the only reason for limited stock market participation. Rather, recent research emphasizes that people tend to hold fewer risky assets such as stocks in their portfolio if they are more vulnerable to income shocks. For example, borrowing constraints (Guiso, Jappelli, and Terlizzese, 1996), labor income risks (VissingJorgensen, 1998b), home ownership (Fratantoni, 1998), and entrepreneurial risks (Heaton and Lucas, 2000) are found to deter stock market entry. Moreover, these factors have smaller effects on people who have larger wealth. Holtz-Eakin, Joulfaian, and Rosen (1994) find that people are willing to take more risks if they receive a large inheritance.

In this paper, I develop a life-cycle model to show how market imperfections may interact with

Hui Guo is an economist at the Federal Reserve Bank of St. Louis. Bill Bock provided research assistance. heterogeneous wealth to generate limited stock market participation. Many factors, such as successful entrepreneurial effort, life-cycle savings, precautionary savings, and inheritance, explain wealth inequality. To keep the model manageable, I focus on three key elements, namely, different investment opportunities (stocks and bonds), credit market imperfections, and inheritance. In the model, although the stock return is higher than the bond return, only people with wealth over a certain threshold own stocks. This occurs for two reasons. First, there is a fixed cost to entering the stock market. Second, people face a borrowing rate that is higher than the saving rate so that they cannot arbitrage by selling bonds and buying stocks. As a result, wealthy households accumulate more wealth and pass on a greater inheritance to their families than poor households do. In the long run, wealth is unequally distributed and wealthy households own almost all stocks.

Some other mechanisms have explained limited stock market participation. Becker (1980) shows that the most patient agent owns all capital in the long run. Allen and Gale (1994) argue that the less risk-averse person is more likely to hold stocks. Constantinides, Donaldson, and Mehra (2000) stress the life-cycle pattern of shareholdings.

Asset returns and limited stock market participation are two closely related issues. However, recent research (i.e., Constantinides, Donaldson, and Mehra, 2000; Polkovnichenko, 2000; and Yaron and Zhang, 2000) has had difficulty explaining the two simultaneously in general equilibrium models. Therefore, I address asset returns and limited stock market participation separately in this paper. First, the asset return is accepted as given when I explain why there is limited stock market participation. Then limited stock market participation is accepted as given when I discuss its effect on the asset return. Nevertheless, we ultimately need to develop a general equilibrium framework that explains both simultaneously, but this is beyond the scope of this paper.

Limited stock market participation may have large effects on asset prices. The risk of the stock market return is measured by its covariance with shareholders' consumption growth in the standard framework, the consumption-based Capital Asset

\footnotetext{
1 Mehra and Prescott (1985) argue for an equity-premium puzzle: the observed equity premium is too large to be explained by existing theories.
} 
Pricing Model. Mehra and Prescott (1985) calculate this covariance using aggregate consumption data and find that it is too small to explain the observed equity premium unless we believe that investors are extremely risk averse. ${ }^{2}$ This is the so-called equity premium puzzle. In their calculation, Mehra and Prescott assume that everyone holds stocks so that they can use aggregate consumption instead of shareholders' consumption. This assumption is inconsistent with the data because not everyone holds stocks. Recent research finds that limited stock market participation does help explain the equity premium puzzle. Using the Panel Study of Income Dynamics data, Mankiw and Zeldes (1991) find that shareholders' consumption is more volatile and more positively correlated with stock market returns than non-shareholders' consumption. Brav and Geczy (1996) and Vissing-Jorgensen (1998a) document a similar phenomenon using the Consumption Expenditure Survey data. In contrast, Guo (2000) explores the connection between limited stock market participation and asset prices by calibrating a heterogeneous agent model in which only one type of agent holds stocks. Under reasonable parameterizations, the simulated data match the first two moments of the risk-free rate and the stock market return.

A related issue is whether the most recent bull market is brought about by the increase in stock market participation. According to the Survey of Consumer Finance data, the stock market participation rate has increased from 31.7 percent in 1989 to 48.8 percent in 1998 . However, stockholdings remain extremely concentrated. For example, the wealthiest 10 percent of U.S. households owned 85 percent of total stocks and mutual funds in 1998 , only slightly lower than the 86 percent owned in 1989. Wolff (2000) also reports that the participation rate drops sharply if small shareholders are excluded. Therefore, there is little change in the concentration of stock ownership and the most recent bull market is unlikely to be explained by the increase in the stock market participation rate. ${ }^{3}$ Given that stock prices fluctuate widely in historical data, the most recent run-up in stock prices may be deviations from the trend.

Limited stock market participation might also help reconcile some macroeconomic anomalies. For example, although rich people own almost all stocks, their consumption share is relatively small. This explains why aggregate consumption is not very responsive to the stock price fluctuation. How- ever, the effects of limited stock market participation on business cycles have not been fully explored yet. Future research along this line should improve our understanding of the economy.

The paper is organized as follows. I first present some stylized facts and then use an overlapping-generations model to help explain limited stock market participation and wealth inequality. In the last section I discuss the implications for asset prices.

\section{SOME STYLIZED FACTS}

In this section, I summarize some stylized facts about financial markets and stock market participation.

- The stock return is persistently higher than the risk-free rate over long horizons.

- Very wealthy households own almost all stocks and other investment assets.

- The share of wealth held by very wealthy households is positively correlated with stock prices.

- The intergenerational transfer is an important channel through which wealth inequality is preserved over time.

\section{Stocks Outperform Risk-Free Assets Over Long Horizons}

The stock return is much higher than the riskfree rate. During the period 1871 1998, the real continuously compounding stock market return was about 7.0 percent per year and the risk-free rate was only 2.4 percent. ${ }^{4}$ The difference is dramatically amplified by the compounding effect. If you invested one dollar in large company stocks at year-end 1925, you would have had $\$ 1,370.95$ by year-end 1996. On the other hand, investments of one dollar in short-term government bonds grew to only $\$ 13.54$ over the same period (Ibbotson Associates, 1997).

\footnotetext{
2 See Kocherlakota (1996) for a survey of recent research on this issue.

3 Heaton and Lucas (1999) make a similar argument. They also explore some other explanations for the most recent stock price run-up.

4 These returns were calculated from the historical data constructed by Robert Shiller, which is available from his homepage $<$ http://aida.econ.yale.edu/ $\sim$ shiller/ $>$. The risk-free rate may be overestimated because it is the return on primary commercial paper in Shiller's data. The annual real return on treasury bills is 0.6 percent for the period 1926-96 (Ibbotson Associates, 1997).
} 


\section{Figure 1}

\section{Annualized Equity Premium Over a 30-Year Horizon}

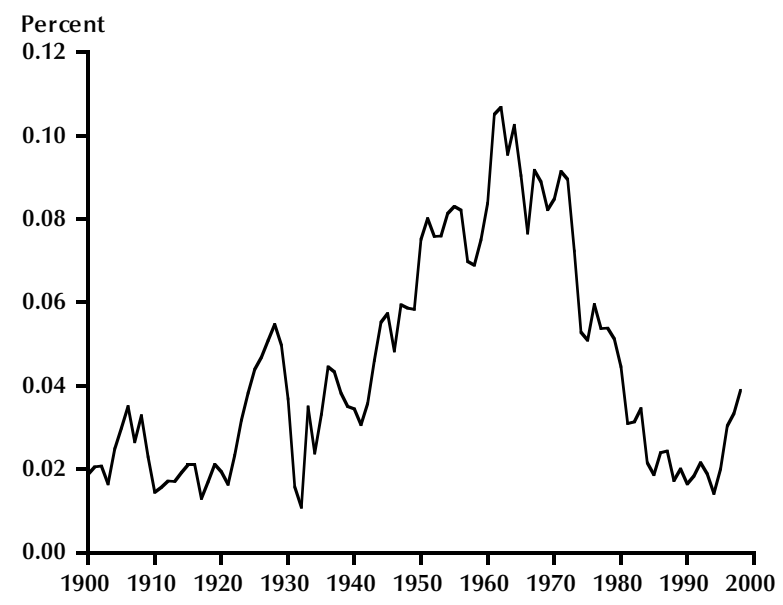

SOURCE: Shiller's Data. See footnote 4.

Fama and French (1988), among many others, also document a mean-reverting process in stock prices. This is often interpreted as meaning that stocks are not as risky in the long run as they are in the short run. In Figure 1, I plot the annualized equity premium over a 30-year horizon. For example, the value corresponding to the year 1997 is the average equity premium over the period 1968-97. The equity premium over a long horizon is always positive, even for periods that include the 1929 stock market crash.

However, it is not my intention to advocate stock market investing. First, Samuelson (1994), among others, is skeptical about these finite sample results. He argues that "if you adhere to the dogma that stocks must beat bonds in the long-enough run, there is no P/E level that the market averages out to at which you will take in sail. A Ponzi bubble is ever possible, and given past psychologies of boom and bust, ever-higher $\mathrm{P} / \mathrm{E}$ ratios become a self-fulfilling prophecy..." (Samuelson, 1994, p.19). Second, the stock market could be very volatile in the short run, and it is rational for people not to participate in stock markets if their wealth is too little to absorb large shocks to stock prices. Heaton and Lucas (2000) argue that even wealthy households should hold fewer stocks if they have significant proprietary income.

\section{Figure 2}

\section{Assets Held by the Richest 10 Percent, 1983-1998}

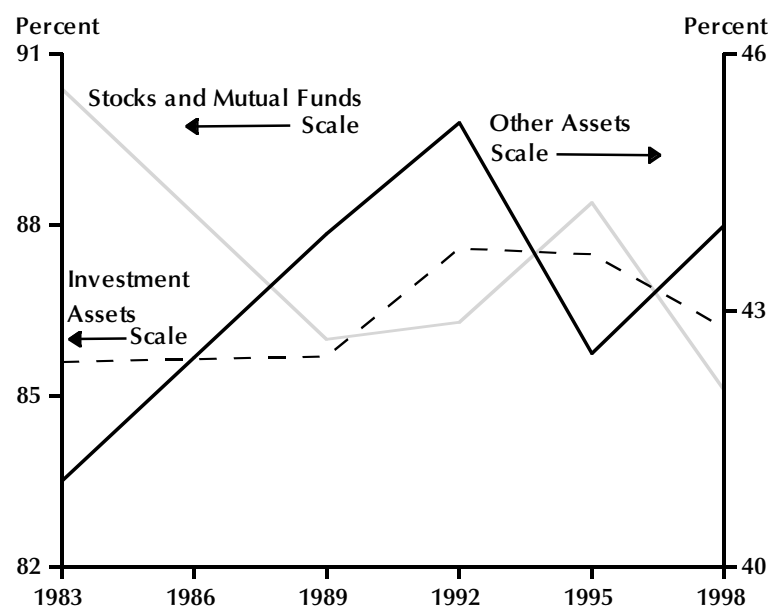

SOURCE: Wolff (2000).

\section{Very Wealthy Households Own Most Stocks}

Stocks are highly concentrated in the hands of very wealthy households. In 1998, the richest 10 percent of U.S. households owned 85 percent of total stocks and mutual funds. They also held most other investment assets, including financial securities, trusts, business equity, and non-home real estate. In fact, they owned 86 percent of total investment assets. However, they had only 44 percent of the other assets, including principal residence, deposits, life insurance, and pension accounts. As shown in Figure 2, their shares of stocks and mutual funds, total investment assets, and other assets are relatively stable over the period 1983-98.

Portfolio compositions are also quite different between the very wealthy and the average households, as shown in Figure 3. The principal residence is the most important asset for average U.S. households, which accounted for 65.9 percent of total assets for the poorest 80 percent of U.S. households in 1995. They also allocated 11.1 percent in liquid assets, 8.5 percent in pension assets, and 12.2 percent in investment assets. Conversely, the richest 1 percent put 78.5 percent of their total wealth in investment assets, 6.4 percent in their principal residence, 7.7 percent in liquid assets, and 4.7 percent 


\section{Figure 3}

\section{Portfolio Compositions: Top 1\% Richest and Bottom $80 \%$ Poorest}

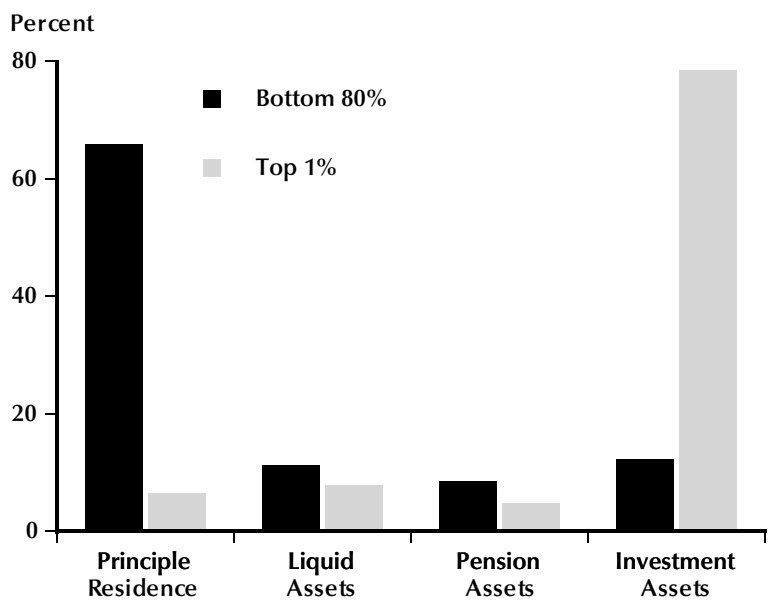

SOURCE: Wolff (1998).

in pension assets. Therefore, very wealthy households have a larger share of risky assets in their portfolios than average households do.

\section{Wealth Distribution Over Time}

Wolff (1995) finds that wealth inequality moves closely with stock prices. His results are reproduced in Figure 4, which plots the share of wealth held by the richest 1 percent of U.S. households and the detrended stock prices for the period 1922-98.

It is clear that these two variables move together, with a correlation coefficient of about 0.61 . There are two reasons. First, the wealthiest 1 percent own almost all stocks, whereas the principle residence is the most important asset held by the average U.S. households. Second, stock prices are much more volatile than the prices of other wealth components, including principle residence. Changes in the valuation of existing assets are thus dominated by fluctuations in the stock market (Ludvigson and Steindel, 1999).

\section{Inheritance and Wealth Inequality}

There are many factors that explain wealth inequality, such as successful entrepreneurial effort, life-cycle savings, precautionary savings, and inheritance. Here, I want to stress the empirical relevance of inheritance, which is a key element of the model presented in the next section.

\section{Figure 4}

\section{Wealth Distribution and Detrended Stock Prices}

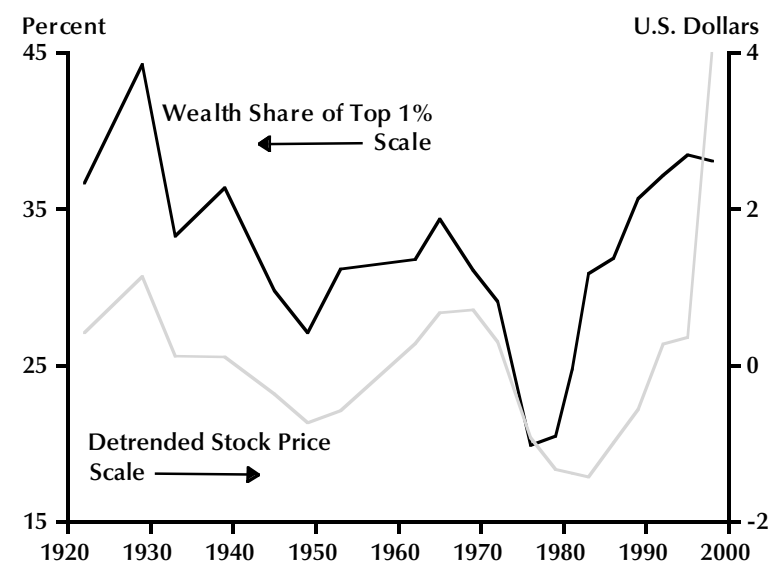

SOURCE: Wolff (1995) and Wolff (2000) for wealth share; Shiller's data for stock prices.

Inhaber and Carroll (1992) argue that inheritance is one of the most important sources of wealth for the richest people, while it is a minor source of assets for most others. For example, 80 percent of the U.S. population claims never to have inherited any assets, and only 1 percent of the population admits to having inherited assets of $\$ 110,000$ or more (Inhaber and Carroll, 1992, p. 73). Moreover, in both 1988 and 1989, more than one third of the 400 wealthiest Americans listed their primary source of wealth as inheritance, according to Forbes magazine.

Kotlikoff and Summers (1981) argue that intergenerational transfers account for the vast majority of aggregate U.S. capital formation. Dynan, Skinner, and Zeldes (2000) also find that inheritance is crucial in explaining the different saving pattern between the rich and the poor.

\section{A LIMITED STOCK MARKET PARTICIPATION MODEL}

For simplicity, I adopt an overlapping generation model with bequest motives, which is similar to the model studied by Galor and Zeira (1993). While Galor and Zeira emphasized the importance of different education opportunities in explaining wealth inequality, I assume that households have different investment opportunities-they can invest in either stocks or bonds. The stock return 
is higher than the bond return; however, there is a fixed stock market entry cost. In the credit market, banks accept deposits and make loans and the household faces a borrowing rate that is higher than the saving rate. I show that, initially, only households with endowments over a certain threshold find it optimal to hold stocks because of the fixed entry cost and the wedge between the saving rate and the borrowing rate. Moreover, some households that initially hold stocks eventually leave the stock market because their relatively small endowments do not allow them to leave a large bequest. Rich households, however, always hold stocks and accumulate wealth faster than poor households do because they enjoy a higher rate of return on their assets. As a result, wealth is unequally distributed and rich people will hold all stocks in the long run.

\section{Model Setup}

There is a continuum of households in an economy that persists forever. At time $t$, each household, say $i$, has a new cohort born, $h_{t}^{i}$. The new cohort receives a bequest, $M_{t}^{i}$, from a parent, $h_{t-1}^{i}$, which can be invested in stocks or bonds. At time $t+1$, he receives labor income, $L$, and the payoff from his earlier investments. ${ }^{5}$ After leaving bequest $M_{t+1}^{i}$ to his one child, $h_{t+1}^{i}$, he consumes the rest of his wealth and exits the economy.

It is costly to enforce loan contracts. Cohorts can save or borrow only through banks, which have the lowest enforcement costs. Banks raise money by issuing bonds, which promise a gross rate of return, $R_{b}$. I assume that the enforcement cost is proportional to borrowers' leverage ratio and a cohort can borrow only at the rate $R_{b}(1+D / W)$, where $D$ is his outstanding debt and $W$ is his net worth. ${ }^{6}$ A cohort can also invest in stocks, which offer a higher rate of return, $R_{s}$, than bonds do. However, there is a fixed stock market entry cost $F>0$. The fixed entry cost can be interpreted as informational costs and factors that affect stock market participation decisions, as discussed in the introduction.

For simplicity, I assume that the gross stock return, $R_{s}$, and the gross bond return, $R_{b}$, are constant and that $R_{s}>R_{b}$ in the baseline model. However, adding noise to stock returns does not change the results in any qualitative way as long as stocks are better investments than bonds, in the sense that mean returns to stocks are larger than mean returns to bonds.
Lastly, there is a progressive tax, $\tau_{b}$, on inheritance, which will be discussed in more detail in the next section.

\section{Maximization Problem}

Since cohorts differ only in their endowments and bequests, I ignore the superscript $i$ and subscript $t$. Instead, I denote $M_{t}^{i}$, the bequests received by a $t$-cohort, as $M$; and I denote $M_{t+1}^{i}$, the bequests left by a $t$-cohort, as $B$.

Cohorts have identical preferences, which depend on consumption, $C$, and bequests, $B$. The utility function is

$$
\operatorname{Max}_{\{C, B\}} \alpha \log (C)+(1-\alpha) \log \left[\left(1-\tau_{b}\right) B\right],
$$

where $\alpha$ is the relative weight given to consumption.

The maximization of equation (1) is subject to budget constraints. If a cohort decides to stay out of stock markets and invest all his endowments in bonds, his budget constraints are

$$
C+B \leq M R_{b}+L .
$$

Otherwise, he chooses to pay the fixed entry cost $F$ to invest in stocks and his budget constraints are

$$
C+B \leq(M+D-F) R_{s}+L-D R_{b}\left(1+\frac{D}{M-F}\right),
$$

where $D$ is the amount that he borrows from the bond market and $R_{b}[1+D /(M-F)]$ is the rate at which he can borrow because his net wealth is $M-F$ after he pays the fixed cost.

The progressive estate tax is defined by equation (4), for which only bequests that exceed a maximum level $\bar{B}$ are taxed:

$$
\tau_{b}=\begin{array}{ll}
0 & \text { if } B \leq \bar{B} \\
\tau & \text { if } B>\bar{B} .
\end{array}
$$

The maximization is done in two steps. A cohort first maximizes his total wealth, $W_{e}$, which is the sum of the payoff to the first period's investments and labor income. He then decides how to

\footnotetext{
5 Galor and Zeira (1993) show that heterogeneity in labor income leads to wealth inequality. Here I want to stress the importance of heterogeneity in investment opportunities on wealth distribution. To ensure a clear demonstration, I assume that all cohorts receive the same labor income, $L$. Adding Galor and Zeira's heterogeneous labor income should not change these results in any qualitative way.

6 In a general equilibrium setting, Bernanke, Gertler, and Gilchrist (1999) show that the cost of external funds depends negatively on firms' net worth relative to the gross value of capital.
} 
allocate total wealth between consumption and bequests.

Maximization of Wealth. A cohort does one of two things: either (i) invests all his endowments in bonds and his second period total wealth is given by

$$
W_{e}=M R_{b}+L,
$$

or (ii) pays the fixed entry cost, $F$, to participate in the stock market and his second period total wealth is given by

(6)

$$
\begin{aligned}
W_{e} & =\max _{\{D\}}(M+D-F) R_{s}+L-D R_{b}\left(1+\frac{D}{M-F}\right) \\
& =\frac{\left(R_{s}-R_{b}\right)^{2}(M-F)}{4 R_{b}}+(M-F) R_{s}+L .
\end{aligned}
$$

Because $W_{e}$ is a linearly increasing function of endowments, $M$, in equations (5) and (6), there exists a threshold level of endowment,

$$
M^{*}=\frac{\left(R_{s}+R_{b}\right)^{2}}{\left(R_{s}-R_{b}\right)\left(R_{s}+3 R_{b}\right)},
$$

at which the cohort is indifferent to these investment strategies. Moreover, he chooses to invest in bonds if his endowment is below $M^{*}$ and chooses to invest in stocks otherwise. The total wealth, $W_{e}$, is then given by equation (7), which is a monotonically increasing function of $M$ :

(7) $W_{e}=$

$$
\begin{array}{cc}
M R_{b}+L, & \text { if } M \leq M^{*} \\
\frac{\left(R_{s}-R_{b}\right)^{2}(M-F)}{4 R_{b}}+(M-F) R_{s}+L, & \text { if } M \geq M^{*} .
\end{array}
$$

Consumption and Bequests. A cohort chooses consumption, $C$, and bequests, $B$, to maximize equation (1), subject to the estate tax (equation (4)) and the reduced budget constraints (equation (8)):

$$
C+B \leq W_{e},
$$

where $W_{e}$ is defined by equation (7). Clearly, there exist $W_{e}{ }^{*}$ and $W_{e}{ }^{* *}$, such that $W_{e}{ }^{*}<W_{e}^{* *}$, and the optimal after-tax bequest is as follows:

$$
B^{*}=\begin{array}{cc}
(1-\alpha) W_{e}, & \text { if } W_{e} \leq W_{e}^{*} \\
\bar{B}, & \text { if } W_{e}^{*} \leq W_{e} \leq W_{e}^{* *} \\
(1-\alpha)(1-\tau) W_{e}, & \text { if } W_{e}>W_{e}^{* *} .
\end{array}
$$

Denote $W_{e}^{-1}$ as the inverse function of $W_{e}(M)$. It is well defined because $W_{e}(M)$ is a monotonically increasing function of $M$. Define $M^{* *}=W_{e}^{-1}\left(W_{e}^{*}\right)$ and $M^{* * *}=W_{e}^{-1}\left(W_{e}^{* * *}\right)$. It is clear that $M^{* * *}$ is greater than $M^{* * *}$.

After substituting equation (7) into equation (9), the optimal after-tax bequest is a function of the endowment $M$ as in equation (10). Here we assume that $M^{* *}$ is greater than $M^{*}$ or that nonshareholders do not have to worry about the estate tax.

(10)

$$
\begin{aligned}
& B^{*}= \\
& (1-\alpha)\left(M R_{b}+L\right), \quad \text { if } M<M^{*} ; \\
& (1-\alpha)\left[\frac{\left(R_{s}-R_{b}\right)^{2}(M-F)}{4 R_{b}}+(M-F) R_{s}+L\right], \\
& \quad \text { if } M^{* \prime \prime} M<M^{* *} ; \\
& \bar{B}, \quad \text { if } M^{* * \prime \prime} M^{\prime \prime} M^{* * *} ; \text { and } \\
& (1-\alpha)(1-\tau)\left[\frac{\left(R_{s}-R_{b}\right)^{2}(M-F)}{4 R_{b}}+(M-F) R_{s}+L\right],
\end{aligned}
$$

otherwise.

\section{The Dynamics of Wealth}

Equation (10) is a first-order difference equation of bequests. The phase diagram is plotted in Figure 5 under the following conditions:

1. $(1-\alpha) R_{b}<1$,

2. $(1-\alpha)\left[\frac{\left(R_{s}-R_{b}\right)^{2}}{4 R_{b}}+R_{s}\right]>1$,

3. $(1-\alpha)(1-\tau)\left[\frac{\left(R_{s}-R_{b}\right)^{2}}{4 R_{b}}+R_{s}\right]<1$.

The first condition ensures at least one stable steady state, which is the same as in Galor and Zeira (1993). The second condition ensures that the wealth diverges in the long run. The third condition is required so that rich people's wealth has a welldefined steady state; otherwise, it goes to infinity.

These conditions hold under reasonable parameterizations. Let us assume that there are 30 years in each period. According to Shiller's data, $R_{b}$ is about 200 percent and $R_{s}$ is about 760 percent. The current highest marginal estate tax rate is 60 percent. Under this parameterization, conditions 1 


\section{Figure 5}

\section{Dynamics of Bequest}

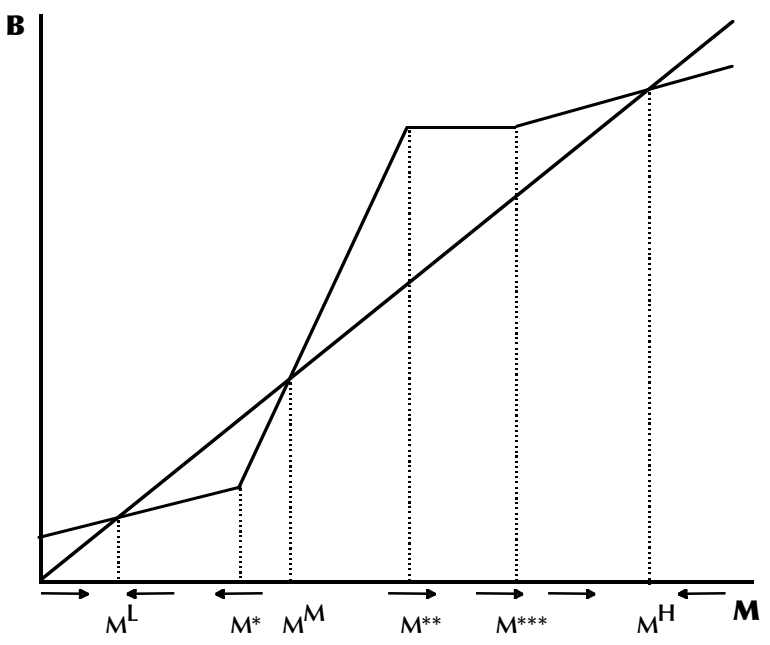

through 3 hold for $0.78<\alpha<0.91$. If the population grows at 2 percent per year, conditions 1 through 3 hold for $0.60<\alpha<0.84 .^{7}$

The following results are shown clearly in Figure 5. First, cohorts with initial endowments less than $M^{*}$ do not hold stocks. Second, there are two stable steady states $M^{L}$ and $M^{H}$. Rich households with initial endowments greater than $M^{M}$ converge to $M^{H}$, and the remaining poor households converge to $M^{L}$. Therefore, wealth is unequally distributed and only rich people hold stocks in the long run. Third, reductions in the fixed entry cost move $M^{*}$ toward the origin and therefore increase stock market participation.

Due to its simplicity, the baseline model does not provide a complete description of data. In particular, the actual wealth distribution is not bimodal, people do move up and down the economic scale, and wealthy households also own a significant amount of bonds in the data. This is because random factors are assumed away in the baseline model. For example, entrepreneurial success or failure can generate mobility in wealth; rich people hold bonds to diversify risks. Incorporations of these considerations should improve our model's prediction. As an example, I will show in the next section of the article that our model can generate a more realistic wealth distribution if stock returns are stochastic.

Stochastic Stock Returns. For simplicity and

\section{Figure 6}

\section{Dynamics of Bequest with Uncertainty}

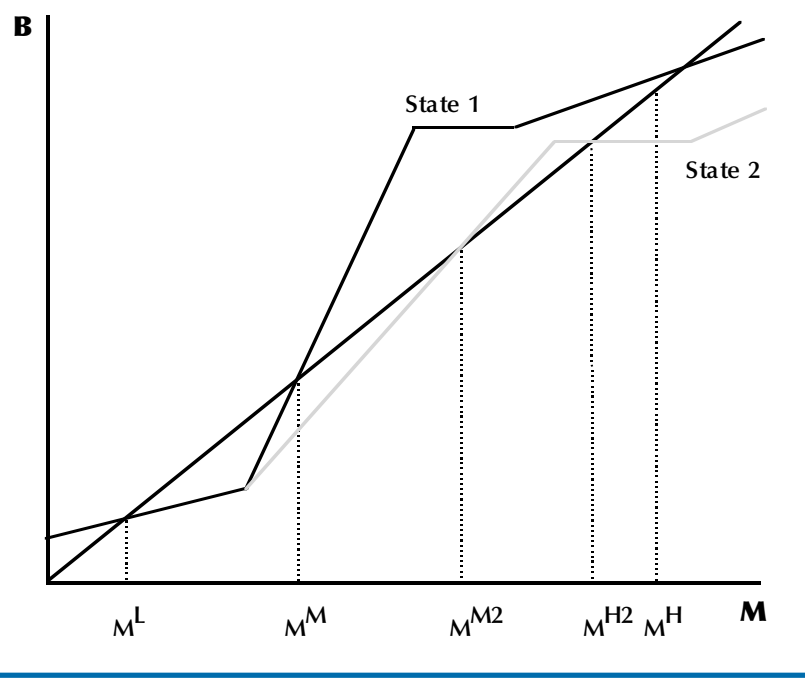

without loss of generality, I assume that stock returns are random realizations of two values and are not serially correlated. Also, the investment decision is made before the stock return is realized. Each cohort now maximizes the expected utility in his first period and his consumption/ bequest decision is the same as in the case of certainty. If conditions 1 through 3 hold in each state, the dynamic of bequests with stochastic stock returns is shown in Figure 6. Note, the portfolio decision is independent from the state because stock returns are not serially correlated.

In the long run, the households with initial endowments less than $M^{M}$ converge to $M^{L}$. The households with initial endowments greater than $M^{M 2}$ converge to the $M^{H 2} / M^{H}$ region. The other households' wealth may fluctuate between $M^{M}$ and $M^{M 2}$, depending on the realizations of the stock return. The stochastic return model thus generates an additional middle class who owns

7 If there is a population growth, conditions 1 through 3 become as follows (where $R_{p}$ is the growth rate of population):

1. $(1-\alpha) R_{b} \frac{1}{R_{p}}<1$,

2. $(1-\alpha)\left[\frac{\left(R_{s}-R_{b}\right)^{2}}{4 R_{b}}+R_{s}\right] \frac{1}{R_{p}}>1$,

3. $(1-\alpha)(1-\tau)\left[\frac{\left(R_{s}-R_{b}\right)^{2}}{4 R_{b}}+R_{s}\right] \frac{1}{R_{p}}<1$. 
some stocks. Moreover, it predicts that the wealth inequality, or the share of wealth held by the rich, increases with stock prices, as observed in the data.

\section{IMPLICATIONS FOR ASSET PRICES}

The asset return is taken as given in the limited stock market participation model presented in the previous section. In this section, I discuss the effect of limited stock market participation on the asset return.

Agents are usually assumed to be homogeneous in economic models for the sake of simplicity. However, asset pricing models with homogeneous agents do not provide a good description for the asset return. They fail to explain why the equity premium is so high (the equity premium puzzle) and why the stock price is so volatile (the excess volatility puzzle).

In modern asset pricing models, agents are risk averse and prefer smooth consumption. The return to an asset thus depends on how well it can be used to smooth agents' consumption. Intuitively, one dollar is more valuable in bad states when consumption is low than one dollar in good states when consumption is high. A stock is thus unattractive, and shareholders demand a positive premium to hold such a stock if its return is low (high) when shareholders' consumption is low (high). Also, the more risk-averse shareholders are, the larger the risk premium they require. It can be shown that the equity premium is equal to $\gamma \sigma_{r, s}$ in a frictionless economy, where $\gamma$ is a measure of relative risk aversion and $\sigma_{r, s}$ is the covariance between the stock return and the shareholder's consumption growth. This is the so-called consumption-based Capital Asset Pricing Model. Assuming that everyone holds stocks, Mehra and Prescott (1985) calculate this covariance using aggregate consumption and find (i) that it is too small to explain the observed equity premium or (ii) that there is an equity premium puzzle.

It also can be shown that asset price $P_{t}$ is equal to the sum of the expected cash flow, $D_{t+i}$, weighted by stochastic discount factor $R_{t+i}$ or

$$
P_{t}=E_{t}\left[\sum_{i=1}^{\infty} R_{t+i} D_{t+i}\right]
$$

In the homogeneous agent model, $R_{t+i}$ is equal to the intertemporal marginal rate of substitution

$$
\beta^{i} \frac{U\left(C_{t+i}\right)^{\prime}}{U\left(C_{t}\right)^{\prime}}
$$

where $\beta$ is the time discount factor, $U^{\prime}$ is the marginal utility, and $C_{t}$ is the aggregate consumption at time $t$. Variations in asset prices thus come from two sources: shocks to the cash flow, $D_{t+i}$, and shocks to the stochastic discount factor, $R_{t+i}$, which in turn are caused by aggregate consumption shocks. Shiller (1981) finds that dividends are too smooth to explain many variations in stock prices. Similarly, Campbell (1991) finds that most variations in stock prices come from innovations in the stochastic discount factor. However, the aggregate consumption is too smooth to generate the volatile stochastic discount factor implied by the financial data. This is the excess volatility puzzle.

The preference is assumed to be time separable in the examples given above. Constantinides (1990) shows that it is possible to use aggregate consumption to generate a volatile stochastic discount factor as well as a large and volatile equity premium in a habit formation model, in which utility depends on both current and past consumption. However, the risk-free rate is very volatile in his model because it is also priced by the same volatile stochastic discount factor. This is easy to understand. Cash flows are stochastic on stocks and are predetermined on bonds. Given that dividends are smooth in the data, this difference is rather small. Stocks and bonds should thus exhibit similar properties, i.e. means and/or variance if they are priced by the same stochastic discount factor. However, the stock return is much higher and much more volatile than the bond return in the data. Therefore, stocks and bonds are not likely to be priced by the same stochastic discount factor. This poses a serious challenge to the homogeneous agent model. 8

Recent research by Guo (2000) suggests that these puzzles might be related to the fact that only a few wealthy people own almost all stocks. He shows that a heterogeneous agent model of limited stock market participation can replicate these phenomena.

There are two types of agents in his model: one is a shareholder and the other is a nonshareholder. They both receive labor incomes, but only the shareholder receives dividends. Labor incomes and dividends follow stochastic processes. Both agents use bonds to diversify the income risk;

\footnotetext{
8 One exception is Campbell and Cochrane (1999), who avoid this problem by choosing a particular habit form so that the risk-free rate is constant. However, they need a very large risk-aversion to explain the puzzles mentioned above. Therefore, they do not really solve the equity premium puzzle.
} 
for example, an agent buys (sells) bonds when his income is above (below) the trend. However, they can borrow from the bond market only up to a limited amount or there are borrowing constraints. The model is calibrated using income processes estimated by Heaton and Lucas (1996), and the simulated data match the mean and variance of stock returns and bond returns under reasonable parameterizations.

Unlike the homogeneous agent model, stocks and bonds may be priced by different stochastic discount factors, as in the model by Guo (2000), because of limited stock market participation. In particular, while bonds are priced by the intertemporal marginal rate of substitution of a nonconstrained agent(s), stocks are always priced by the shareholder's intertemporal marginal rate of substitution. Stocks and bonds are thus priced by different intertemporal marginal rates of substitution when the shareholder's borrowing constraints are binding. The stochastic discount factor for bonds is

$$
\max \left\{\beta^{i} \frac{U\left(C_{t+i}^{s}\right)^{\prime}}{U\left(C_{t}^{s}\right)^{\prime}}, \beta^{i} \frac{U\left(C_{t+i}^{n}\right)^{\prime}}{U\left(C_{t}^{n}\right)^{\prime}}\right\}
$$

and for stocks it is

$$
\beta^{i} \frac{U\left(C_{t+i}^{s}\right)^{\prime}}{U\left(C_{t}^{s}\right)^{\prime}}
$$

where $C_{t}^{s}$ and $C_{t}^{n}$ are consumption of the shareholder and the non-shareholder, respectively. It is clear that the former is larger and smoother than the latter because borrowing constraints put a lower bound on the discount factor of bonds, but not stocks. Therefore, in Guo's model, the bond return is low and smooth while the stock return is high and volatile, as observed in the data.

Intuitively, bonds are desirable and are priced at a premium because they can be used to diversify income shocks. Stocks are not desirable because they cannot be used to diversify income shocks. The precautionary saving motive thus lowers only the risk-free rate, but not the stock return. This echoes Weil's (1989) argument that the equity premium puzzle is indeed a risk-free rate puzzle. To see this, the equity premium in Guo (2000) is equal to $\gamma \sigma_{r, s}+r_{s}^{f}-\min \left\{r_{s}^{f}, r_{n}^{f}\right\}$, where $\gamma$ is the relative risk aversion coefficient, $\sigma_{r, s}$ is the covariance between shareholder's consumption and the stock return, and $r_{s}^{f}\left(r_{n}^{f}\right)$ is the shadow risk-free rate of the shareholder (non-shareholder). The equity premium is larger in Guo's model than in the representative agent model for two reasons. First, there is an extra nonnegative term, $r_{s}^{f}-\min \left\{r_{s}^{f}, r_{n}^{f}\right\}$, reflecting the fact that bonds (stocks) can (cannot) be used to hedge income shocks. This term can be interpreted as a liquidity premium. Second, the covariance between shareholders' consumption and the stock return is larger than the covariance between aggregate consumption and the stock return.

\section{CONCLUSION}

The recent Survey of Consumer Finance data show that stocks are highly concentrated in the hands of a few wealthy people. In this paper, I used an overlapping-generations model to help explain this limited stock market participation and discussed its effect on asset prices. However, other implications, such as its effect on business cycles, have not been fully explored yet. Future research along this direction should improve our understanding of the economy.

\section{REFERENCES}

Allen, Franklin and Gale, Douglas. "Limited Market Participation and Volatility of Asset Prices." American Economic Review, September 1994, 84, pp. 933-55.

Becker, Robert. "On the Long-Run Steady State in a Simple Dynamic Model of Equilibrium with Heterogeneous Households." The Quarterly Journal of Economics, 1980, 95, pp. 375-82.

Bertaut, Carol. "Stockholding Behavior of U.S. Households: Evidence from the 1983-1989 Survey of Consumer Finances." Review of Economics and Statistics, May 1998, 80(2), pp. 263-75.

Bernanke, Ben; Gertler, Mark and Gilchrist, Simon. “The Financial Accelerator in a Quantitative Business Cycle Framework." Working Paper No. 6455, National Bureau of Economics Research, 1998.

Brav, Alon and Geczy, Christopher. "An Empirical Resurrection of the Simple Consumption CAPM with Power Utility." Memo, University of Chicago, 1996.

Campbell, John. "A Variance Decomposition for Stock Returns.” Economic Journal, March 1991, 101, pp. 15779. and Cochrane, John. "By Force of Habit: A Consumption-Based Explanation of Aggregate Stock 
Market Behavior." Journal of Political Economy, April 1999, 2(107), pp. 205-51.

Constantinides, George. "Habit Formation: A Resolution of the Equity Premium Puzzle." Journal of Political Economy, June 1990, 98(3), pp. 519-43.

; Donaldson, John and Mehra, Rajnish. "Junior Can't Borrow: A New Perspective on the Equity Premium Puzzle." Working Paper No. 6617, National Bureau of Economics Research, 2000.

Dynan, Karen; Skinner, Jonathan and Zeldes, Stephen. "Do the Rich Save More?” Working Paper No. 7906, National Bureau of Economics Research, 2000.

Fama, Eugene and French, Kenneth. "Permanent and Temporary Components of Stock Prices.” Journal of Political Economy, April 1988, 96(2), pp. 246-73.

Fratantoni, Michael. "Homeownership and Investment in Risky Assets.” Journal of Urban Economics, July 1998, 44(1), pp. 27-42.

Galor, Oded and Zeira, Joseph. "Income Distribution and Macroeconomics.” Review of Economic Studies, 1993, 60(1), pp. 35-52.

Guiso, Juigi; Jappelli, Tullio and Terlizzese, Daniele. "Income Risk, Borrowing Constraints and Portfolio Choice." American Economic Review, March 1996, 86(1), pp. $158-72$.

Guo, Hui. "Business Conditions and Asset Prices in a Dynamic Economy.” Working Paper 2000-31A, Federal Reserve Bank of St. Louis, 2000.

Heaton, John and Lucas, Deborah. "Portfolio Choice and Asset Prices: The Importance of Entrepreneurial Risk." Journal of Finance, June 2000, 55(3), pp. 1163-98. and "Stock Prices and Fundamentals." NBER Macroeconomics Annual, 1999, pp. 213-42. and "Evaluating the Effects of Incomplete Markets on Risk Sharing and Asset Pricing." Journal of Political Economy, June 1996, 104(3), pp. 44387.

Holtz-Eakin, Douglas; Joulfaian, David and Rosen, Harvey. "Entrepreneurial Decisions and Liquidity Constraints." Rand Journal of Economics, July 1994, 25(2), pp. 334-47.
Inhaber, Herbert and Carroll, Sidney. How Rich is Too Rich? Income and Wealth in America. New York: Praeger Publishers, 1992.

Kocherlakota, Narayana. "The Equity Premium: It's Still a Puzzle." Journal of Economic Literature, March 1996, 34(1), pp. 42-71.

Mankiw, Gregory and Zeldes, Stephen. "The Consumption of Stockholders and Nonstockholders." Journal of Financial Economics, March 1991, 29(1), pp. 97-112.

Kotlikoff, Laurence and Summers, Lawrence. "The Role of Intergenerational Transfers in Aggregate Capital Accumulation." Journal of Political Economy, August 1981, 89(4), pp. 706-32.

Ludvigson, Sydney and Steindel, Charles. "How Important is the Stock Market Effect on Consumption?" Federal Reserve Bank of New York Economic Policy Review, July 1999, 5(2), pp. 29-51.

Mehra, Rajnish and Prescott, Edward. "The Equity Premium: A Puzzle.” Journal of Monetary Economics, March 1985, 15(2), pp. 145-61.

Polkovnichenko, Valery. "Heterogeneous Labor Income and Preferences: Implications for Stock Market Participation.” Working Paper, University of Minnesota, 2000.

Samuelson, Paul. "The Long-Term Case for Equities.” Journal of Portfolio Management, October 1994, 21(1), pp. 15-24.

Shiller, Robert. "Do Stock Prices Move Too Much to Be Justified by Subsequent Changes in Dividends?" American Economic Review, June 1981, 71(3), pp. 421-36.

Schwert, William. "Why Does Stock Market Volatility Change Over Time?” Journal of Finance, 1989, 44(5), pp. 1115-53.

Vissing-Jorgensen, Annette. "Limited Stock Market Participation.” Working Paper, MIT, 1998a.

"An Empirical Investigation of the Effect of Non-Financial Income on Portfolio Choice." Working Paper, MIT, 1998b.

Weil, Philippe. "The Equity Premium Puzzle and the RiskFree Rate Puzzle.” Journal of Monetary Economics, November 1989, 24(3), pp. 401-21. 
Wolff, Edward. "Recent Trends in Wealth Ownership, 1983 1998.” Working Paper No. 300, Jerome Levy Economics Institute, 2000.

"Recent Trends in the Size Distribution of Household Wealth.” Journal of Economic Perspectives, July 1998, 12(3), pp. 131-50.

Top Heavy: A Study of the Increasing Inequality of Wealth in America. New York: The Twentieth Century Fund Press, 1995.

Yaron, Amir and Zhang, Harold. "Fixed Costs and Asset Market Participation." Revista de Analisis Economico, 2000, 15, pp. 89-109. 
RE VIE W

48 MAY/JUNE 2001 